\title{
Nanoimprint Lithography of Topology Optimized Photonic Crystal Devices
}

Olsen, Brian Bilenberg; Frandsen, Lars Hagedorn; Nielsen, Theodor; Vogler, Marco; Borel, Peter Ingo; Kristensen, Anders

Published in:

Conference on Lasers and Electro-Optics and 2006 Quantum Electronics and Laser Science Conference. CLEO/QELS 2006.

Link to article, DOI:

10.1109/CLEO.2006.4628228

Publication date:

2006

Document Version

Publisher's PDF, also known as Version of record

Link back to DTU Orbit

Citation (APA):

Olsen, B. B., Frandsen, L. H., Nielsen, T., Vogler, M., Borel, P. I., \& Kristensen, A. (2006). Nanoimprint Lithography of Topology Optimized Photonic Crystal Devices. In Conference on Lasers and Electro-Optics and 2006 Quantum Electronics and Laser Science Conference. CLEO/QELS 2006. [4628228] IEEE. https://doi.org/10.1109/CLEO.2006.4628228

\section{General rights}

Copyright and moral rights for the publications made accessible in the public portal are retained by the authors and/or other copyright owners and it is a condition of accessing publications that users recognise and abide by the legal requirements associated with these rights.

- Users may download and print one copy of any publication from the public portal for the purpose of private study or research.

- You may not further distribute the material or use it for any profit-making activity or commercial gain

- You may freely distribute the URL identifying the publication in the public portal 


\title{
Nanoimprint Lithography of Topology Optimized Photonic Crystal Devices
}

\author{
Brian Bilenberg ${ }^{1}$, Lars Hagedorn Frandsen², Theodor Nielsen ${ }^{1}$, Marko Vogler ${ }^{3}$, \\ Peter Ingo Borel ${ }^{2}$, and Anders Kristensen ${ }^{1, *}$ \\ ${ }^{I}$ MIC - Department of Micro and Nanotechnology, Nano $\cdot D T U$, Technical University of Denmark, DK-2800 Kongens Lyngby, Denmark \\ ${ }^{2} \mathrm{COM} \cdot \mathrm{DTU}$, Department of Communications, Optics and Materials, Nano $\bullet D T U$ \\ Technical University of Denmark, DK-2800 Kgs Lyngby, Denmark \\ ${ }^{3}$ micro resist technology GmbH, Köpenicker Str. 325, D-12555 Berlin, Germany \\ ${ }^{*}$ Corresponding author, e-mail: ak@mic.dtu.dk
}

\begin{abstract}
We demonstrate a nanoimprint process for fabrication of photonic crystal devices. The nanoimprint process, defining stamp patterns in a thin e-beam resist, yields improved pattern replication compared to direct e-beam writing of the devices.

C2006 Optical Society of America

OCIS codes: (130.3120) Integrated optics devices; (220.4000) Microstructure fabrication
\end{abstract}

The optical performance of photonic crystal $(\mathrm{PhC})$ components is highly sensitive to the nanometer feature sizes of the components. Even small deviations may be devastating for the functionality and/or the target operating frequency. Recently, topology optimization has proven to be a strong tool for the optimization of PhC components [1]. Such optimized structures do, however, require an even higher degree of fidelity in the pattern transfer.

Along with the requirements of obtaining a high aspect ratio between pattern depth and size, these issues form a serious challenge for photonic crystal- and wire-based technologies. Approaches based on direct electron beam lithography (EBL) and a soft etch mask have been successfully demonstrated. However, the low etch resistance of the electron beam resist mask limits this approach to resist thicknesses of $100 \mathrm{~nm}$ and above, compromising the lithographic resolution. Application of hard masks or transfer layers also limits the resolution and pattern transfer fidelity. We present a nanoimprint process for fabrication of photonic crystal devices (and other nanoscale applications) in silicon. High resolution and high aspect ratio of the transferred pattern is obtained by exploiting a high-resolution negative EBL resist for silicon stamp fabrication in combination with nanoimprint lithography (NIL) in a thermoplastic resist with high etching resistance.

(a)

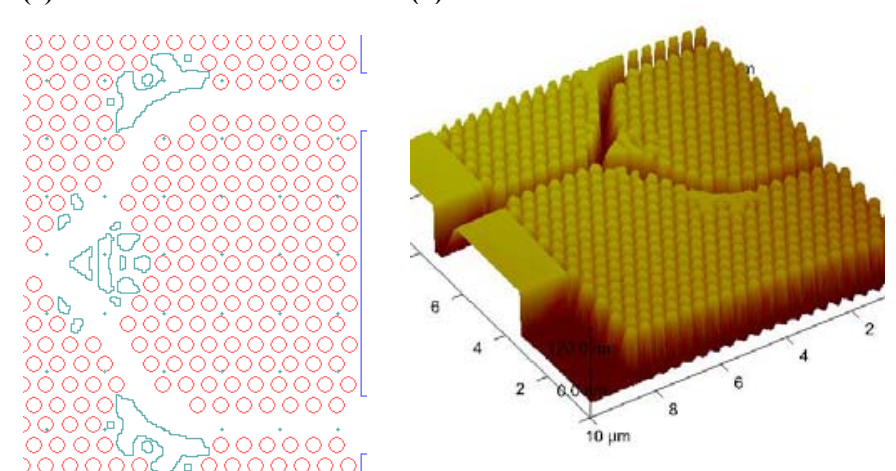

(c)

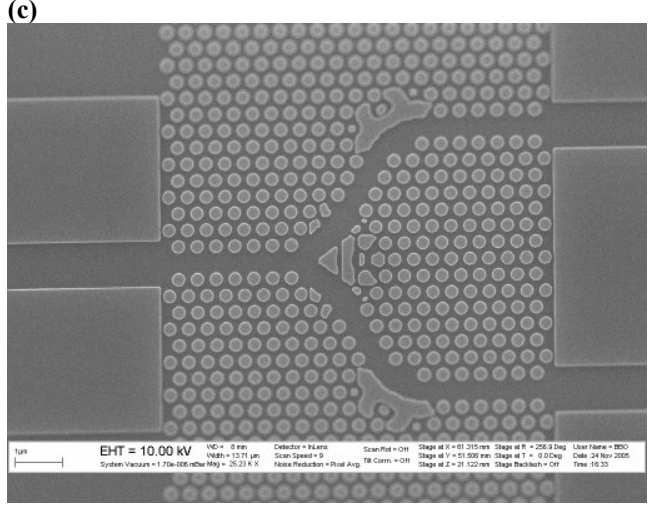

Fig. 1. Silicon nanoimprint stamp, fabricated by $100 \mathrm{kV}$ electron beam lithography in the negative, high resolution resist TEBN-1, and reactive ion etching. The design shown in panel (a) is compared with an AFM image in panel (b) and a scanning electron micrograph picture of the silicon stamp in panel (c).

The silicon stamp is fabricated by $100 \mathrm{kV}$ EBL (JEOL JBX9300FS) in a $50 \mathrm{~nm}$ thick film of TEBN-1 [2] on a silicon substrate at an exposure dose of $9 \mathrm{mC} / \mathrm{cm}^{2}$. The written structures are developed in methyl isobutyl ketone (MIBK) for $20 \mathrm{~s}$, rinsed in isopropyl alcohol (IPA) and subsequently transferred $100 \mathrm{~nm}$ into the silicon substrate by a highly anisotropic reactive ion etch [3]. After etching the silicon, any remaining resist is removed in oxygen plasma prior to deposition of an anti sticking layer from $\mathrm{C}_{4} \mathrm{~F}_{8}$ plasma and imprinting.

An $80 \mathrm{~nm}$ thick film of $\mathrm{mr}-\mathrm{I} \mathrm{T} 85$ (4 wt\%) is spincoated onto a silicon-on-insulator (SOI) substrate at a spin speed of $3000 \mathrm{rpm}$ and baked at $150^{\circ} \mathrm{C}$ for $5 \mathrm{~min}$ on a hot plate. The stamp is imprinted using an EVG imprint tool (EVG 520HE). The optimum imprint parameters for replication of the PBG structures are found to be: Imprint 


\section{CTuK2.pdf}

temperature $140^{\circ} \mathrm{C}$, imprint time $10 \mathrm{~min}$, and imprint pressure $13 \mathrm{bar}$. The imprint takes place in vacuum $(0.01$ mbar) and the stamp and substrate are separated at a temperature of $60^{\circ} \mathrm{C}$. The imprint parameters result in a complete filling situation of the stamp in the PBG structured areas, resulting in $100 \mathrm{~nm}$ deep holes in the mr-I T85 resist. The nanoimprinted patterns are transferred into the top $320 \mathrm{~nm}$ thick silicon layer of a SOI substrate by using an optimized $\mathrm{SF}_{6}$-based inductively coupled plasma (ICP) etch. The etch selectivity of silicon over mr-I T85 is 9:1 (Silicon:mr-I T85) [4] which allows for pattern transfer of the imprinted holes through the device silicon layer of the SOI substrate.
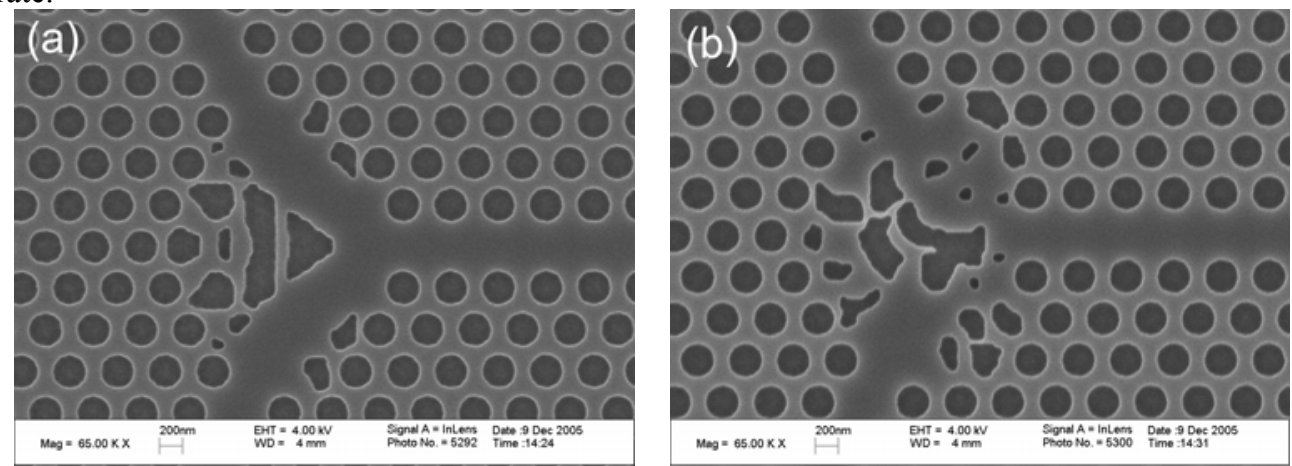

Fig. 2. SEM images of nanoimprinted, topology optimized photonic crystal beam splitters. The holes are etched into the

top-silicon layer (thickness $320 \mathrm{~nm}$ ) of a silicon-on-insulator wafer.

The lithographic result of our imprint process is compared to devices fabricated by direct electron beam writing of the etch mask. For direct writing, the positive resist ZEP520a was exposed at $100 \mathrm{kV}$, using the same EBL tool as used for stamp fabrication. The ZEP520a resist has a selectivity of $\sim 5$ compared to silicon in the ICP etch, hence, a layer of 100-150 nm is necessary to transfer the pattern into the silicon layer. The results are shown in Figure 3, where the detailed and complex features in the central part of a splitter device fabricated by direct EBL (left) and with NIL (right) are compared with each other and with the design pattern (middle). As seen from the figure, the NIL process replicates the nanoscale pattern details with a quality comparable or better than by direct electron beam writing.

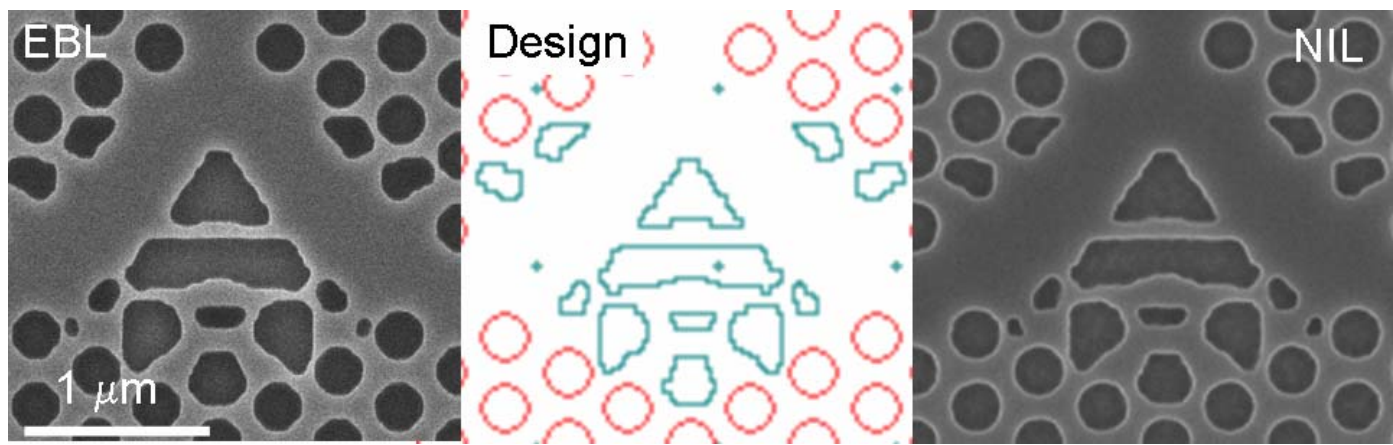

Fig. 3. Comparison of pattern replication with direct electron beam writing (left) and nanoimprint lithography (right).

In conclusion, we have presented a nanoimprint lithography process for photonic crystal devices (and similar pattern transfer applications), based on high resolution $100 \mathrm{kV}$ electron beam lithography in a $50 \mathrm{~nm}$ film of the negative resist TEBN-1 for stamp fabrication, thermal nanoimprint in a $100 \mathrm{~nm}$ film of mr-I T85 nanoimprint resist, and pattern transfer by reactive ion etching into silicon. A resulting high resolution in combination with high aspect ratio of the transferred pattern is obtained by exploiting the high resolution of TEBN-1 for stamp fabrication and the high etch resistance of the mr-I T85 nanoimprint resist for pattern transfer. The obtained lithographic results of the nanoimprint process match the results obtained by direct electron beam writing of a resist mask for reactive ion etching of the nanostructures

[1] P. I. Borel, L. H. Frandsen, A. Harpoth, M. Kristensen, J. S. Jensen, and O. Sigmund, "Topology optimised broadband photonic crystal Ysplitter", Electronics Letters 41, 69-71 (2005).

[2] TEBN-1 by Tokuyama Corp., Tokyo, Japan www.tokuyama.co.jp

[3] B. Bilenberg, S. Jacobsen, M. S. Schmidt, L. H. D. Skjolding, P. Shi, P. Bøggild, J. O. Tegenfeldt, and A. Kristensen, ”High Resolution $100 \mathrm{kV}$ Electron Beam Lithography in SU-8", J. Microelectronic Engineering, accepted for publication (2005)

[4] T. Nielsen, D. Nilsson, F. Bundgaard, P. Shi, P. Szabo, O. Geschke, and A. Kristensen, "Nanoimprint lithography in the cyclic olefin copolymer, Topas, a highly UV-transparent and chemically resistant thermoplast”, J. Vac. Sci. Technol. B 22, 1770-1775 (2004). 